\title{
Research on Teaching Practice of Academic Literature Reading for Higher Vocational Students
}

\author{
Yongliang Xie* Yan Zhao Wenxian Shi \\ Logistics and Supply Chain Management School,Zhejiang Technical Institute of Economics \\ 66 Xue Zheng Street,Hangzhou,310018, Zhejiang,China \\ * E-mail of the corresponding author: 564059974@qq.com
}

\begin{abstract}
Reading academic literature and writing literature review are common assignments in university education.Although there are many sources describing the process of literature reading and literature review, teachers and students still face many difficulties in accomplishing these tasks.As an informal course, this course is the final report of eight years of the authors' teaching literature reading in combination with course/graduation practical activities.At present, our school has three-year and four-year students, and the teaching requirements of them are different. This paper suggests that the academic literature reading guide should be integrated into the teaching framework of literature review or become a separate course, so as to meet the cultivation needs of them.Moreover, this paper describes the teaching process of the literature reading for all freshmen majoring in logistics, and takes the causes of the bullwhip effect as a case study to demonstrate some details of critical reading. The results show that students present enough confidence, interest and sense of achievement after class to alleviate their anxiety and fear of literature reading.
\end{abstract}

Keywords:literature review, literature reading,critical reading,mind map

DOI: $10.7176 / \mathrm{JEP} / 12-24-02$

Publication date:August $31^{\text {st }} 2021$

The research is financed supported by "13th Five-Year Plan" Zhejiang Province Higher Education Reform Research Project "Research and Practice of Improving the Literature Reading Ability of Students majoring in Logistics Management of Higher Vocational Education at Different Levels" (JG20180779).

1.Introduction

Academic literature is the wisdom crystallization of scientific research, the best carrier of theoretical knowledge and technical methods, and the best road sign to understand and engage in the current research direction, while literature review is an effective means to explore ideas and research problems.As a result,Literature review writing is a common assignment in four-year university courses ,junior college courses, and graduate education(Ridley, 2008), is an important genre (Cooper, 1988),Literature reading is the basis of literature review writing.

However, Chinese higher education administrators generally believe that literature review seems to be a matter of undergraduate and graduate students, so most higher vocational colleges do not offer literature reading and literature review courses, which is also one of the reasons that higher vocational college students' reading behaviors are characterized by superficial (Yongliang Xie, 2021). The value of literature review courses is that students are able to develop the skills required to complete their studies, such as literature retrieval, efficient and critical reading, organizing literature review structure, which will have a positive impact on their lives.In the actual teaching, the survey found that literature reading, even literature review strategy for higher vocational college students is still demand focus. The students are eager for careful guidance and lots of practice from their teachers.

This paper is a summarization that our project team members have used over the past eight years to teach students how to read academic literature in combination with course/graduation practical projects. The purpose of the course of literature reading is to help students to master the basic skills of literature retrieval and reading academic literature and obtaining the required information from it .

This course lasts for 4 sessions with 8 hours, which can be used as a single course for all freshmen majoring in logistics, or as the first half of literature review course which has 8 sessions with 16 hours, the second half is literature review writing.

\section{Literature review theory}

\subsection{Definition of literature review}

From the discussion at the beginning of the course, it is the definition and structure of literature review that puzzles most students. The most common literature review assignments are organized by one author per paragraph, rather than by a specific topic, because students look literature review as a summary rather than an analysis and synthesis process. 
Literature review is defined by writing process (Riley, 1997), order (Machi \& McEvoy, 2009), or category (Zorn \& Campbell, 2006).The University of Southern California(2021) classifies them into Argumentative, Integrative, Historical, Methodological, Systematic, and Theoretical Review.

Wellington et al.(2005) argued that literature review involves searching, collecting, prioritizing, purposefully reading, and finding key issues and topics, which are then presented and discussed critically.Literature review is an understanding of the overall state of the literature by investigating, summarizing and synthesizing the existing literature on the topics of interest (Pautasso, 2013).Jonathan(2014) defines literature review as a synthesis that provides the reader with a recent summary of theoretical and empirical data on a particular topic.

\subsection{Why should literature review be conducted}

First, literature review identifies possibilities for future research by looking for good research examples, identifying opportunities for improvement, or gaps in subject knowledge (Froese,1998).In fact, the impetus to do a literature review may come from answering questions in a list of core research papers (Sutherland etal.,2011), or from random reading and discussion among peers.

Second, writing a good literature review requires good skills, such as skills ranging from finding and evaluating relevant material to synthesizing various kinds of information, from critical thinking to interpretation, evaluation, analysis and citation (Budgen D, 2006; Jill etal., 2006), these skills run through a person's life.

Third,due to the increasing number of scientific publications in recent years (Rapple C,2011), it is impossible for scientists to examine in detail every new paper that is relevant to their interest (Erren TC, 2009), therefore, recent literature needs to be regularly summarized in a professional manner (Ketcham CM, 2007), to bring new insights and be widely read (Hampton SE, 2011).

It can be seen that literature review is a comprehensive research activity, which requires a lot of time and energy, and at the same time, it can develop people's comprehensive skills.

\subsection{General process for literature review}

Although there are a number of textbooks in the market that specialize in literature review (Hart, 2001;ZhangLi,2008), but on the one hand, students have no time to read the whole book; on the other hand, most textbooks are short of details and questions.In general, literature review writing follows a seven-step process (Machi, L. A., \& McEvoy, B. T.,2009), of which the first five steps are closely related to reading.

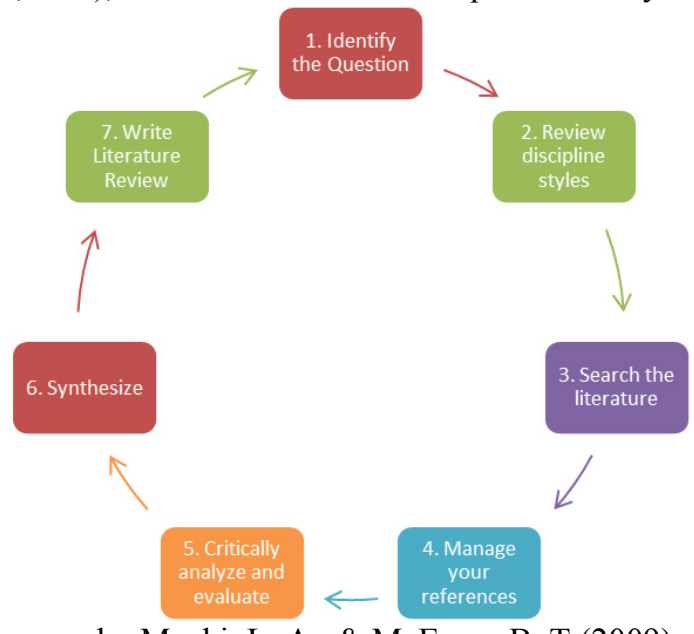

To sum up, academic literature reading is closely related to literature review.Considering that the current higher vocational education system of our university has both three-year college education and four-year graduate education, and the teaching requirements of them are different, this paper suggests that academic literature reading should be integrated into the teaching framework of literature review or become a separate course, so as to take into account the cultivation needs of the two different types of students. The best way to master the literature review skill is to present, compare, and analyze literature review cases from journals with different quality.

\section{Teaching process of literature reading}

This includes identifying sources and research topics, literature retrieval, reading demonstration and literature discussion. 


\subsection{Determine research topics and literature types}

First of all, the teacher provides sufficient time for students to discuss freely and finds the appropriate concept words by analyzing the problems.

Secondly, let the students understand the characteristics of the research topic: well-defined questions, Interesting a series of recent papers related to the author's work that need to be summarized,an important aspect of the field, in preparation for a literature review, a sufficient number of sources should be available.

Finally, choose the right and avoid the wrong types of literature.The literature that should be reviewed include peer-reviewed journal articles like empirical or theoretical or literature review,government reports,conference proceedings,conference reports and dissertations, There are also trade journal articles, magazine articles, and newspaper articles, e-books,images, maps, standards, patents, statistics, company and industry information. At the same time, some unreliable sources should be avoided, such as editable Wikipedia and Baidupedia, which can be written by many people, updated or changed indefinitely, and often the information may be incorrect and easy to be manipulated.Textbooks, magazines, blogs, newspapers, other media, and non-academic sources are not primary sources of literature review because they do not provide important details such as methodology and the status of the literature.

\subsection{Literature retrieval and management articles}

literature retrieval includes where and how to retrieve the articles?how to get the full text ?and how to manage articles?.The whole process is as follows:

STEP1: Define the keywords.It focuses on selecting the topic, determining the keywords, selecting the appropriate database and search engine, choosing the appropriate search method, stopping searching.Break the topic into main concepts, then define keywords for each concept.Keywords are free text words and phrases.The database search strategy uses a combination of free text and subject headings. Usually look for keywords in the title and abstract.General strategies include: using a thesaurus to identify synonyms;Search for concepts on search engines such as Google Scholar and scan search results for alternative words and phrases,checking related abstracts or articles for alternative words, phrases, and topic headings (if the database uses topic headings).In addition, there are using truncated and wildcard searches, and use adjacency searching for more accurate searching with subject keywords, using boolean logic(AND, OR and NOT), citation Searching.For those who just enter the research field, it is better to search for the review done by predecessors, of which keywords are review,state of the art,future direction.

STEP2: Start the search.Mainly introduce the common databases, such as China Academic Journal network, China National Knowledge Network and Superstar provided by the university library; The public library's English language literature retrieval database,such as Springerlink, Highwire Press, EBSCO(ASP+BSP), Elseiver SD, Emerald, Web of Science, Scopus, CiteSeer, Worldwide Forum, JSTOR.Internet search engine like Google Scholar, Microsoft Academic,Baidu Scholar,etc.But students must be warned about the need to search multiple databases to avoid missing relevant articles.For example, Elsevier's Science Direct mainly indexes journals published by Elsevier.

STEP3: Trace references.Once a number of relevant journal articles have been identified, one way to find more articles is by looking at a list of references to those articles (backward searching), as well as papers cited since their publication (forward searching).

STEP4: Record the search.By jotting down the names of the journals you come across frequently during the search, it will become clear which ones stand out in the field of research.Track the use of different search terms and think about the reasons for the differences in each search result.Keep a list of keywords and keywords combinations that return the best results.It reduces the time spent in searching and generates a list of terms common to the research area.

STEP5: Use the citation manager.If a large number of papers need to be filtered and tracked, a document Manager like Endnote, Reference Manager, or Zotero, can be downloaded and setup for saving papers directly from the website or database. This is helpful to form a preliminary draft of the review while reading the literature (Torraco RJ,2005), to both improve efficiency and prevent false attributions.However, once the complete paper cannot be obtained temporarily, it is necessary to establish a list of PDF files that cannot be accessed immediately, so that other strategies can be used for retrieval, or directly contact the author from the author's web page and his paper to obtain the full text.

STEP6: Follow up the literature.A number of databases and publishers now offer alerts, such as Table-ofContents (TOC) alerts, Citation alerts, and Keyword alerts, which are useful for keeping up with the latest published papers and research topics. These services provide email alerts listing the title, author and abstract of a new paper.

STEP7: Iterative search. When the same authors and studies are cited in many journal articles, they reach saturation and stop searching.At this point, the title and abstract of each source are checked, the unqualified papers are eliminated and discarded, and the students are asked to read at least 15 to 20 papers to make the final 
ideal papers list.

\subsection{Reading Demonstration}

\subsubsection{Selecting sample paper and discussion focus}

The structure and characteristics of empirical journal paper (see Table 1) and strategies for critical reading are emphasized in the discussion for it has a predictable structure, and therefore is selected as a sample and assigned for reading before class.

Table 1. The Structure and Characteristics of Empirical Journal Paper

\begin{tabular}{|c|c|c|c|}
\hline No. & Subsection & Features & Focus of Classroom Discussion \\
\hline 1 & $\begin{array}{l}\text { paper title } \\
\text { and author }\end{array}$ & $\begin{array}{l}\text { author name, publication date, paper } \\
\text { title, journal name and volume } \\
\text { number, and page number. }\end{array}$ & $\begin{array}{l}\text { The source and citation of the paper,The } \\
\text { content and research methods in the title, the } \\
\text { quality of the journal, etc }\end{array}$ \\
\hline 2 & $\begin{array}{l}\text { Abstract and } \\
\text { key words }\end{array}$ & $\begin{array}{l}\text { Block alignment, separate from the } \\
\text { text.The abstract of } 300 \text { words } \\
\text { provides a concise description of the } \\
\text { research.To help determine whether it } \\
\text { is relevant to the research topic.Clear } \\
\text { and easy to understand. }\end{array}$ & $\begin{array}{l}\text { What is the purpose of this paper? } \\
\text { What is a research topic? } \\
\text { Why is it important? } \\
\text { What,if any,theory is used? }\end{array}$ \\
\hline 3 & Introduction & $\begin{array}{l}\text { Typical three-stage routine: } \\
\text { "As the...In the past few years, a lot } \\
\text { of progress has been made, such } \\
\text { as...We can come to the conclusion } \\
\text { that..., and as...And think..., and so } \\
\text { on. } \\
\text { But,...Therefore,....The structure of } \\
\text { this paper is as follows..." }\end{array}$ & $\begin{array}{l}\text { What is the purpose of this paper? } \\
\text { What is the research topic? } \\
\text { Why is it important? } \\
\text { What,if any,theory is used? } \\
\text { What are the key definitions? }\end{array}$ \\
\hline 4 & $\begin{array}{l}\text { Literature } \\
\text { review }\end{array}$ & $\begin{array}{l}\text { A description of the research status } \\
\text { related to the topic of the paper. }\end{array}$ & Previous research methods and results. \\
\hline 5 & Methodology & $\begin{array}{l}\text { information about the data sources } \\
\text { (e.g., samples), the methods used to } \\
\text { collect the data (e.g., survey, } \\
\text { observation, and visit), and the } \\
\text { techniques used to organize and } \\
\text { analyze this data. }\end{array}$ & $\begin{array}{l}\text { What,if any,theory is used? } \\
\text { what samples are used? } \\
\text { How to sample?sample sizes? What are the } \\
\text { characteristics of the samples?How is the data } \\
\text { collected?What are the key definitions? What is } \\
\text { data analysis technology? }\end{array}$ \\
\hline 6 & Results & $\begin{array}{l}\text { Follow the methodology and present } \\
\text { results from data analysis.The results } \\
\text { were used to answer research } \\
\text { questions. }\end{array}$ & What are the results and conclusions? \\
\hline 7 & Discussion & $\begin{array}{l}\text { The results were placed in the context } \\
\text { of the existing literature and whether } \\
\text { they supported or deviated from the } \\
\text { literature was discussed.The } \\
\text { discussion focused on explaining the } \\
\text { proposed findings, pointing out } \\
\text { limitations and gaps in the study, and } \\
\text { providing guidance for future } \\
\text { research. }\end{array}$ & $\begin{array}{l}\text { What are the results,conclusions, additional key } \\
\text { themes? } \\
\text { Do the results support/nonsupport the existing } \\
\text { literature? } \\
\text { Are particular characteristics important to } \\
\text { consider? }\end{array}$ \\
\hline 8 & Conclusion & $\begin{array}{l}\text { They are usually short, briefly } \\
\text { summarizing the overall conclusions } \\
\text { of the study, including why the } \\
\text { findings are important.Generally } \\
\text { speaking, in order to help the reader } \\
\text { better understand the point of the } \\
\text { article. }\end{array}$ & $\begin{array}{l}\text { What is the purpose of this passage? } \\
\text { What is a research problem? } \\
\text { Why is this important? } \\
\text { What's the result? } \\
\text { What conclusions can be drawn from the data } \\
\text { analysis? }\end{array}$ \\
\hline 9 & Reference & $\begin{array}{l}\text { Each source referenced is listed along } \\
\text { with the information needed to find } \\
\text { and access that source.Reference } \\
\text { Style }\end{array}$ & $\begin{array}{l}\text { Comparing the citation styles of Chinese } \\
\text { journals with them, state out the differences. }\end{array}$ \\
\hline
\end{tabular}


Critical reading is active reading that aims to identify arguments, weigh evidence, evaluate sources, find conflicts of interest, and question underlying assumptions, which is fully different from the passive reading of novels.Critical reading is an important skill that helps students become more informed.

In general, college freshmen are bewildered by the critical reading, for the students can't and won't question caused by rote learning which is rooted in high schools commonly, and yet universities may just require students to become critical readers, to master a set of opposite skills they have in high school .

\subsubsection{Strategies for Critical Reading of Academic Literatures}

Stage 1:Pre-reading Strategies

- Make a weekly/daily reading schedule.Read for forty-five minutes with a break of five to fifteen minutes and then continue.Write down your reading speed and see how many pages you read per hour to help you plan better.

- Choose a place to read away from distractions.

- Read while you're paying attention. Try not to read when you're tired or distracted.

- Don't put the reading assignment at the bottom of task list.

- Read every day.If you fall behind on your reading schedule, you must catch up.

- Keep a piece of paper and a pen by your side. What if something happens while you're reading and your brain goes off topic and needs to deal with it later, write it down and be able to focus and continue reading.

- Put your phone on silent or do not disturb mode.

- Create a purpose for your reading and help your brain focus.

Stage 2:While-reading Strategies

It focus on the three-pass method.

The first pass is a quick scan to the paper,with taking five to ten minutes,to carefully read the title, abstract, and introduction,to read the sub-section and its headings and the sentences at the beginning of paragraphs,to ignore the details, to read the summary/conclusion, to skim the references, and to eliminate the articles you've already read.

It's best to ask yourself many questions during the first-pass reading, such as:

- What kind of article is it? Analysis or renovation of existing systems?

- What other papers is related to it? What is the theoretical basis?

- Are the assumptions reasonable? How strong is the evidence?

- What are the main contributions of the paper?

- Is the writing good?

- Summarize the argument, then think again about what the title/summary suggest about the reading of the article and Was it misled by the title/summary, can it be changed, and if so, how and why?

If the answer is clear, go into the second pass.

The second pass spent an hour on reading the paper more carefully, but omitted details such as the proof.It's best to read with a pen in hand and circle, draw, or note key points, or make your own comments on the margins.

- Look carefully at the numbers, charts, and other illustrations in the paper.Pay special attention to the charts.Are axes correctly marked?The error column shows the results so that the conclusion is statistically significant?

- Mark references for further reading to help you learn more about the background of the paper.

- Annotate questions to consider in the margins.Look for unfamiliar words and make sure of understanding any confusing or complex sentences and evidence in the paper.

- Use a pen to annotate and analyze evidence supporting the arguments. This includes short summaries at the end of chapters, arrows/circles/numbers in key paragraphs and sentences, and colored pens to mark key points or main ideas.

- Be able to summarize and evaluate the main purpose of the paper and provide evidence and check the quality of evidence.

- Define key terms in your own words. If you don't understand them, you can use the Internet .Reread your comments after reading the paper to see if you understood them correctly.

- Write it down when you have any problem.As you read again, see if you get answers to these questions. otherwise ask your teacher or classmates.

Sometimes, because the subject is unfamiliar with terms and acronyms, or because the article provides proof or experimental techniques that are difficult to understand at the moment, it is advisable to put the paper aside and read the paper or background material at a more energetic time.

The third pass takes about four to five hours for beginners, and about an hour for experts.

- Read aloud (slowly) to others or self to help think.

- By extracting the structure of the paper and rebuilding it, the purpose of identifying its strengths and weaknesses is realized.

- Relate to the content of other publications and compare the differences and similarities in topics, research 
issues/concepts, research methods, data types and arguments using the matrix method..

- Form an analytical framework, which may include:

(1)What theories are used in the paper?

(2)How do key concepts change and be used?

(3) Is it the policy intention, formal policy, or outcome of implementation under discussion?

(4)Has anyone else tested this theory?If so, under what circumstances?Is the theory, method, and concept mentioned provide an improvement on previous ones, or does it emphasize its limitations? What is the author's point of view in contrast to other points of view in the passage?

Stage 3:Post-reading Strategies

- Reward yourself!Singing, outing, big dinner, etc.

- Interpretative questioning. Does it answer the question raised before the reading?

- Talk about or reread important parts with someone else.

- Immediately after reading, take fifteen minutes to write down as many impressions as you can about what you have read.

- Spend fifteen minutes in a 24-hour period on going over your notes and reciting key points.

- Review and focus on your reading notes and improve your note-taking methods.

- Keep a reading log.After each reading task, write down in your reading log whether you like it and why you like it,Explain the reasons. This helps to analyze and discuss the article carefully.

\subsection{Literature Discussion}

It is important to have an effective discussion based on reading.It is carried out in the form of report by students, discussion by students and teacher, and comment by teacher.students are required to complete the literature reading in groups before class. and one student from each group will present their ideas in the form of multimedia slides and explain in class for at most ten minutes, mainly including:

- Understand research background, proposed scientific problems, experimental methods, data analysis, and results, whether the research ideas are innovative, and whether the experiments and hypotheses are deficient.

- Share their difficulties and the strategies to follow in reading, such as the choice of reading place, comfort level of the environment, number of reading pages at one time, and reading plan.

Followed by a fifteen to twenty minutes discussion session that includes:

- Discuss students' reading difficulties and summarize reading strategies, sharing techniques such as prereading, skim reading,scanning, and in-depth reading.For example, when reading English literature, students are bound to encounter a lot of unfamiliar words and sentences, and ask them to bring them up in class. Teachers use Youdao Online Dictionary to demonstrate operations and explain their meanings, even whole sentences and paragraphs.

- Answer questions, supplement class presentations, and discuss the design of an article, and research implications.

In order to fully mobilize the enthusiasm of students, the teacher conducts a comprehensive assessment according to each student's report, the number and the quality of the questions.Finally, the teacher will make comments, recommendations and summaries according to class reports and discussion contents.It mainly includes: pointing out the shortcomings of the report, supplementing the relevant basic theory and background knowledge, introducing the expression methods of scientific research writing and relevant experimental methods, etc.

\section{Teaching process of analyzing the causes of bullwhip effect as example}

It is well known that the Bullwhip effect is caused by six factors mentioned in textbooks (Gaojuhong, 2012), is it really ?The students are not sure. The teachers and students work together to complete the exploration process.

STEP1: Determine the search keyword :Bullwhip effect + Causes +reviews.

STEP2: Enter Microsoft Academic, find and download the paper of Ranjan (2010) to the target folder. 


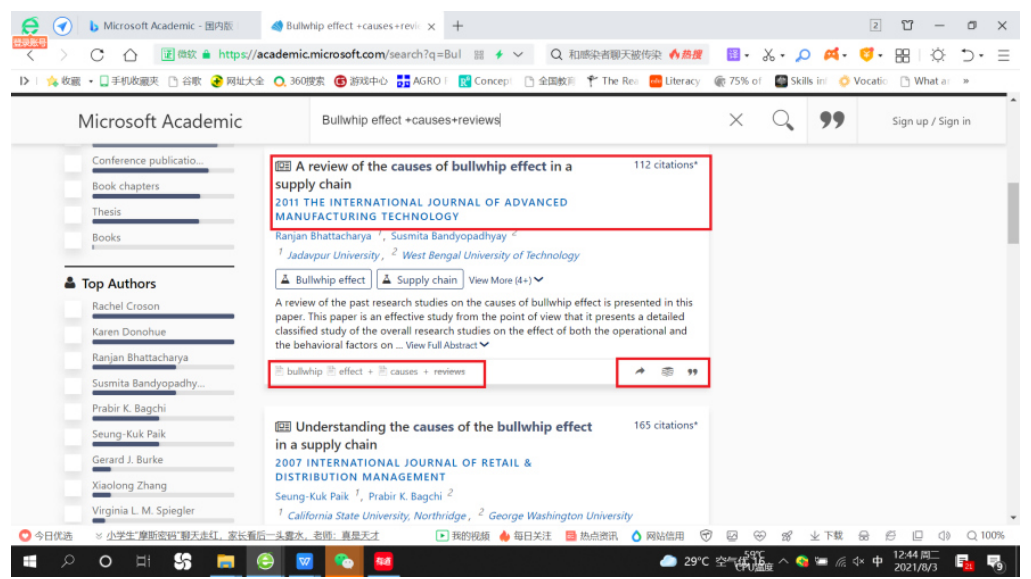

STEP3: Browse the abstract and key words, ask students to answer the focus of the abstract and some questions. Abstract A review of the past research studies on the causes of bullwhip effect is presented in this paper. This paper is an effective study from the point of view that it presents a detailed classified study of the overall research studies on the effect of both the operational and the behavioral factors on bullwhip effect. A total of 19 causes of bullwhip effect have been shown here. We have identified the various gaps of research in the past research studies. An overview of the steps taken by the industries in order to tackle the bullwhip effect is also provided at the end of this paper. Directions for further research studies are also provided in each subsection of this study and athe end of this paper.

Keywords Bullwhip effect · Supply chain · Operational causes - Behavioral causes

why?detail subfactors?

how many of Each?show

details?

important!surely?and so on

STEP4: the first pass to browse the text subheadings, and grasp the key information such as outline and diagram. The first key information is the outline of the literature.

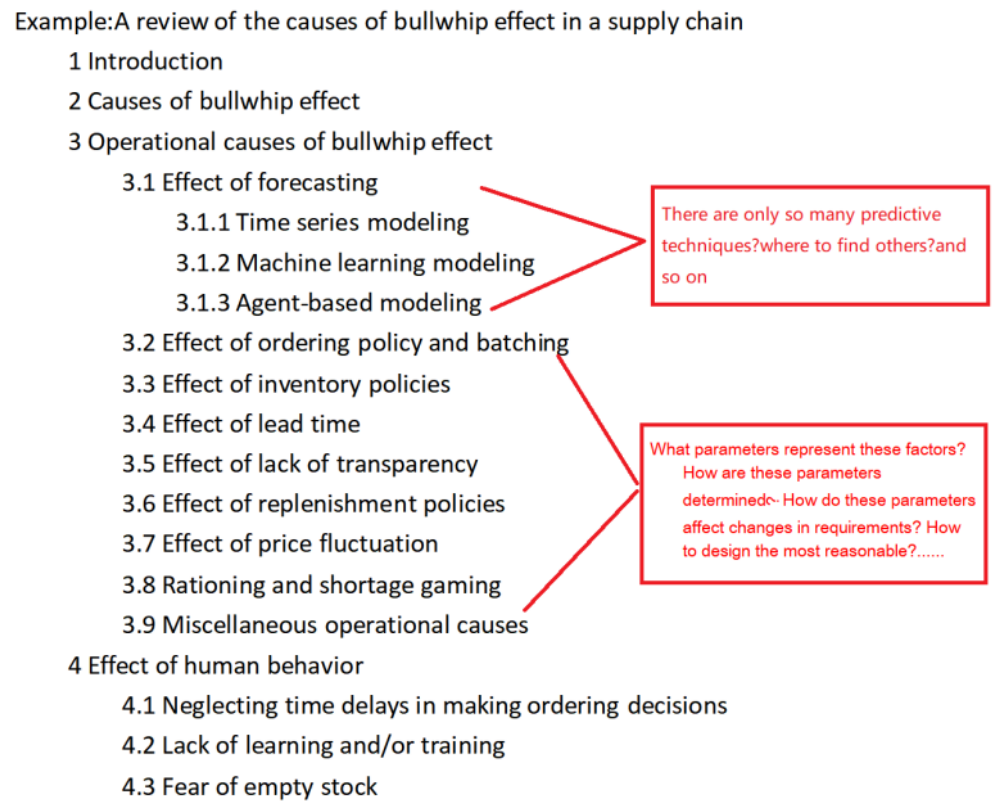

The second key information is the classification of the causes of the bullwhip effect. Compare the similarities and differences between the textbook and this article. What are the reasons? 


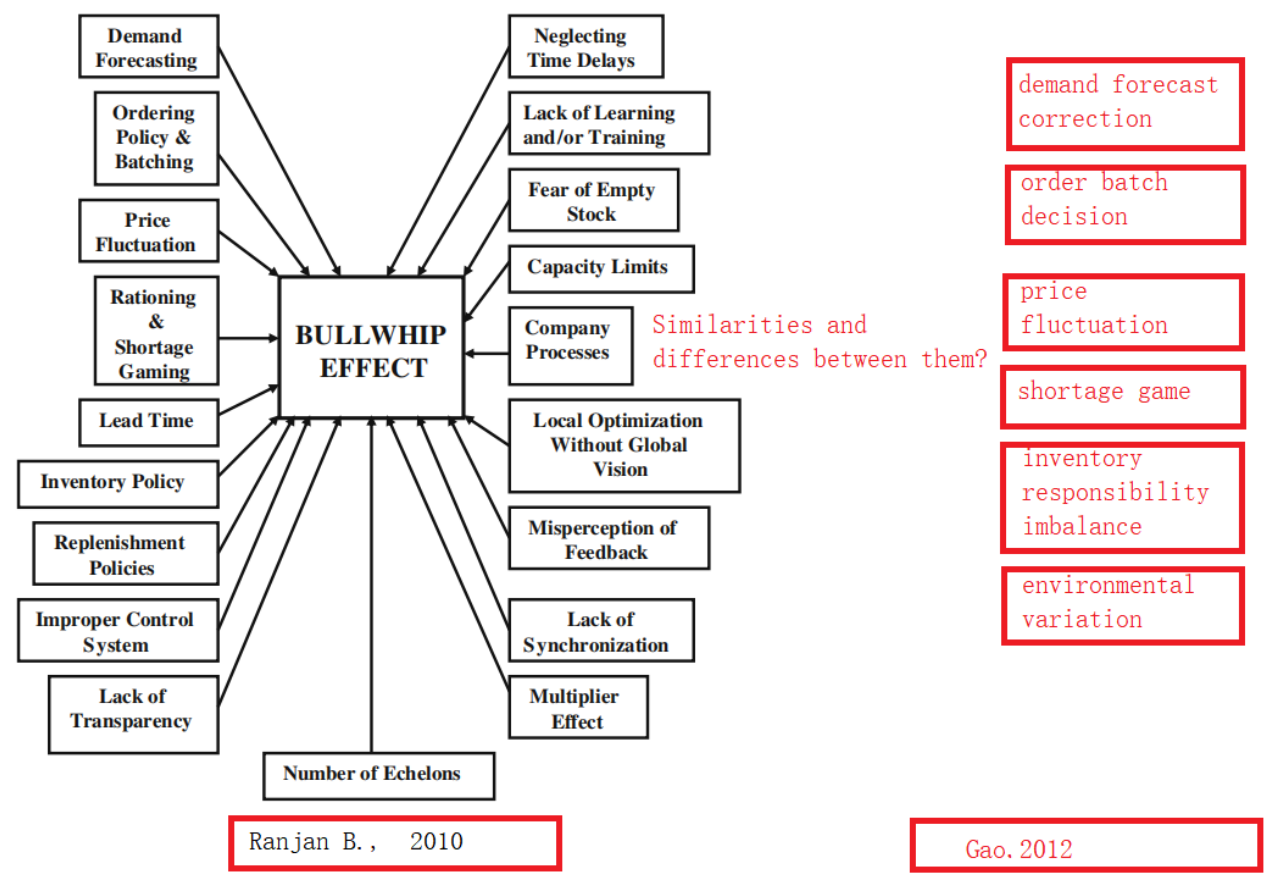

STEP5: Read the conclusion, seek the novel points, think and write down the problems, such as if economic recession is a factor, then the business cycle is also a factor, and then how does it affect the operation in each stage of the business cycle? What indicators do represent business cycle in

We have observed that there are more factors whose effects have not been studied. One such factor is the effect of economic recession on bullwhip. The effect of recession on BWE can also be an interesting and unearthed research advance? area in view of the recessive trend of the world economy.

How does the recession affect the bullwhip effect?and economic cycle?global natural diaster?

STEP6: Read the reference list, find and download the literature in combination with the direction of personal interest, such as demand prediction, and then do a forward or backward search, or search demand prediction +review to find new literature review. By reading this step by step, students will find more and more valuable points of interest, and over time,to form a rich knowledge spectrum of supply chain management discipline, this part can be used as homework for students to complete with mind mapping.Various citation styles are also introduced, including APA ,MLA,Chicago/Turabian Style, IEEE Style, and compared with the citation styles of Chinese journal articles.

STEP7: Do classroom discussion.Answer the difficult words and sentences that students encounter in the process of reading the literature, and discuss the terms related to the bullwhip effect in the text. These words are often the topics or keywords for future literature search. Students can search and read the literature in depth again according to the sub-topic;or combine these words in pairs, or add industries to form new research topics, such as Joint Optimization Model of Demand Forecast and Inventory in the Fashion Industry Under the Make to Stock Model.

\section{Summarize}

Higher demands placed on students and teachers. As the literature reading course is set in the first semester, the knowledge structure of students is not systematic enough, which leads to the interaction difficulties between teachers and students at the beginning of teaching. Therefore, teachers should choose literature with moderate difficulty and applicable and review literature;Teachers should constantly ask new questions during reading demonstration and discussion, and inspire students to put forward new ideas and praise them. The teacher himself has rich literature reading and teaching experience, a wide range of knowledge, solid theoretical foundation, good at questioning and summary.

Appropriate class size. There are a large number of students in the classroom, it is difficult for teachers to fully take care of the needs of each student, and for students to have the opportunity to participate in every stage of the teaching process, which decreases the teaching effect and not to ensure the fairness of the teaching evaluation standards.It is recommended that class size is limited to 15 students.

The teaching evaluation criteria of the course.Different from traditional courses, literature reading courses pay more attention to the evaluation of students' learning process, focusing on the examination of students' 
learning attitude, extracurricular preparation and the degree of participation in classroom teaching. At the end of the course, students are required to submit a course paper. Teachers will assess students' performance in class, especially their ability to raise and communicate questions, together with the paper.In the specific teaching practice, the corresponding grade evaluation method is formulated in accordance with the above principles: the final grade of the course consists of topic report, classroom discussion and attendance rate, with weights of $30 \%$, $50 \%$ and $20 \%$ respectively (see Table 2 ).

Table 2. Evaluation index and its weight of class achievement

\begin{tabular}{|l|l|c|}
\hline \multicolumn{1}{|c|}{ Assessment items } & \multicolumn{1}{|c|}{ Assessment points } & weight \\
\hline Topic report & $\begin{array}{l}\text { Whether the content of the report reflects current progress in the } \\
\text { subject area. } \\
\text { Whether the content is correct. } \\
\text { whether the presentation is clear and well-organized. }\end{array}$ & $30 \%$ \\
\hline Classroom discussion & $\begin{array}{l}\text { Ability and depth to ask questions. } \\
\text { Willingness to participate in discussion. }\end{array}$ & $50 \%$ \\
\hline Attendance assessment & Attendance rate & $20 \%$ \\
\hline
\end{tabular}

After eight years of efforts, due to its features with openness, reflection and discussion, the literature reading course promotes students' interest in learning, helps students master the methods of literature retrieval and the strategies details of reading academic literature, and lays a good foundation for the subsequent professional study, scientific research activities and work.

\section{References}

Budgen D, Brereton P (2006) .Performing systematic literature reviews in software engineering. Proc 28th Int Conf Software Engineering, ACM New York, NY, USA, pp. 1051-1052.

Cooper, H. M. (1988). Organizing knowledge synthesis: A taxonomy of literature reviews. Knowledge in Society, $1,104-126$

Erren TC, Cullen P, Erren M (2009). How to surf today's information tsunami: on the craft of effective reading. Med Hypotheses 73: 278-279.doi:10.1016/j.mehy.2009.05.002.

Froese, AD(1998). Teaching Students to Write Literature Reviews: A Meta-Analytic Model. Teaching of Psychology, 25,2: 102-105. doi:10.1145/1134285.1134500.

Gaojuhong(2012).Supply chain management.Beijing:Beijing University Press.

Hampton SE, Parker JN (2011) .Collaboration and productivity in scientific synthesis. Bioscience 61: 900-910. doi:10.1525/bio.2011.61.11.9.

Harris M. Cooper(1988).Organizing Knowledge Syntheses: A Taxonomy of Literature Reviews.Knowledge in Society, 1(1),Spring:104-126.

Hart, C. (2001). Doing a literature search. London: Sage.

Jill Jesson \& Fiona Lacey(2006).How to do (or not to do) a critical literature review.Pharmacy Education, 6(2): $139-148$.

Jonathan Cisco(2014).Teaching the Literature Review: A Practical Approach for College Instructors.Teaching \& Learning Inquiry, Volume 2, Issue 2, pp. 41-57.

Ketcham CM, Crawford JM (2007) .The impact of review articles. Lab Invest 87: 1174-1185.

doi:10.1038/labinvest.3700688.

Machi, L. A., \& McEvoy, B. T. (2009). The literature review: six steps to success. Thousand Oaks,

Calif.: Corwin Press.

North Carolina State University Librarie(2021). https://libguides.usc.edu/writingguide/readingresearch

Pautasso M (2013). Ten Simple Rules for Writing a Literature Review. PLoS Comput Biol 9(7): e1003149. doi:10.1371/journal.pcbi.1003149

Ranjan B., Susmita B.(2011).A review of the causes of bullwhip effect in a supply chain.Int J Adv Manuf Technol ,54:1245-1261 .DOI: 10.1007/s00170-010-2987-6.

Rapple C (2011) .The role of the critical review article in alleviating information overload. Annual Reviews White Paper. http://www.annualreviews.org/userimages/ContentEditor/

1300384004941/Annual_Reviews_WhitePaper_Web_2011.pdf.

Ridley, D. (2008). The literature review: a step-by-step guide for students. London: Sage.

Riley, P. (1997). Literature reviews: obtaining perspective. Classroom Teachers and Classroom

Research, 4, 49-54.

Sutherland WJ, Fleishman E, Mascia MB, Pretty J, Rudd MA (2011). Methods for collaboratively identifying research priorities and emerging issues in science and policy. Methods Ecol Evol 2: 238-247. doi:10.1111/j.2041-210X.2010.00083.x.

Torraco RJ (2005) Writing integrative literature reviews: guidelines and examples. Human Res Develop Rev 4 : 356-367. doi:10.1177/1534484305278283. 
Wellington, JAB, C Hunt, G McCulloch \& P Sikes(2005). Succeeding with your Doctorate. California: Sage.

Williams, J. K. (2018). A Comprehensive Review of Seven Steps to a Comprehensive Literature Review. The Qualitative Report, 23(2), 345-349. https://doi.org/10.46743/2160-3715/2018.3374

Yongliang Xie(2021).Current Reading Habits of Higher Vocational College Students in

Zhejiang Technical Institute of Economics.Journal of Education and Practice.Vol.12, No.15:1-6.

ZhangLi(2008).How to Review Literature-Cases and Commments.Beijing:Science Press.

Zorn, T., \& Campbell, N. (2006). Improving the writing of literature review through a literature integration exercise. Business Communication Quarterly, 69(2), 172-183. 